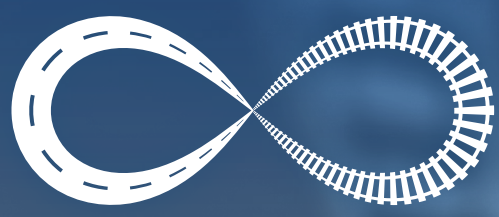

CETRA $^{2018}$

$5^{\text {th }}$ International Conference on Road and Rail Infrastructure 17-19 May 2018, Zadar, Croatia

Road and Rail Infrastructure V

Stjepan Lakušić - EDITOR

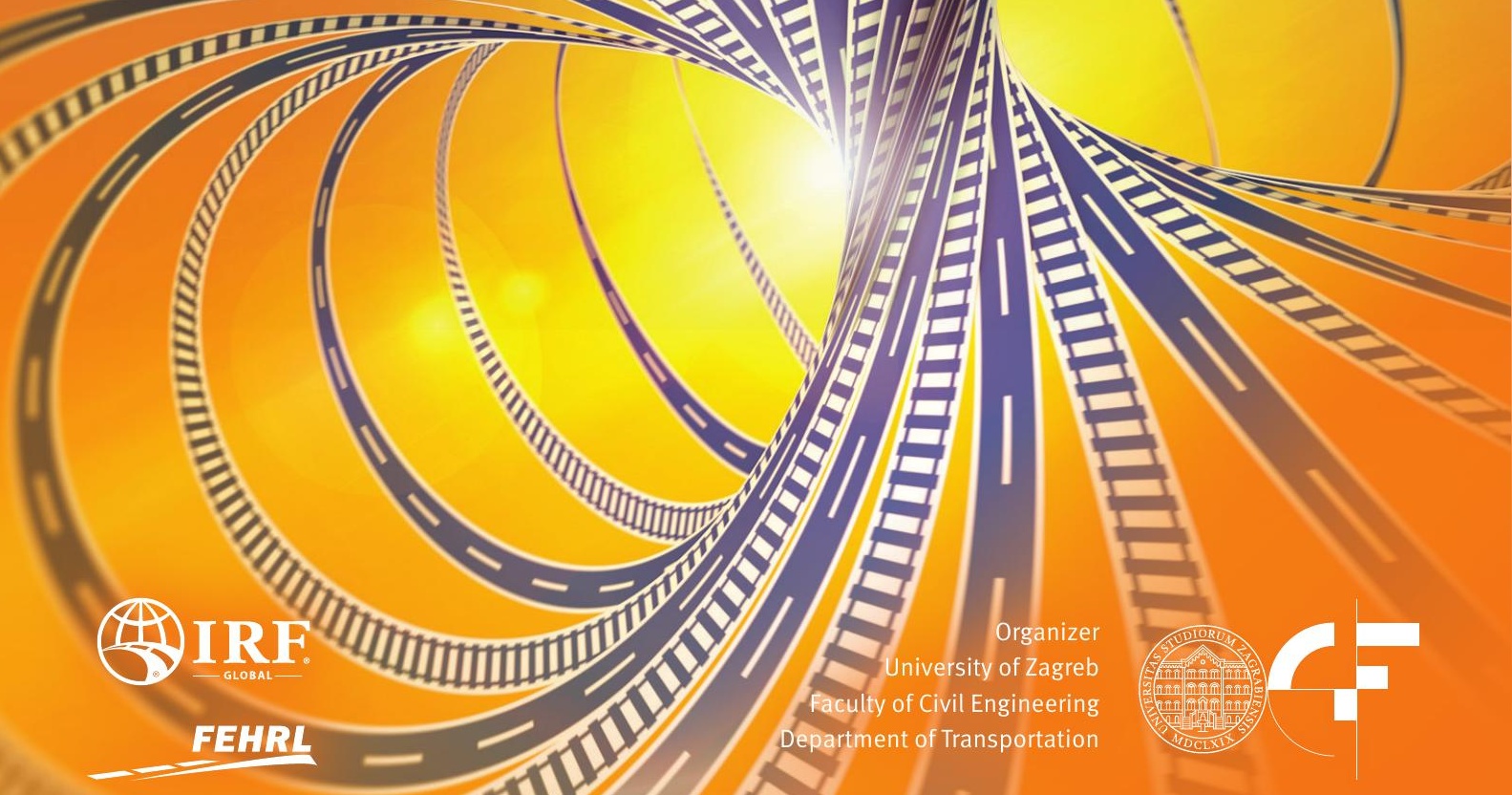




\section{CETRA $^{2018}$}

\section{$5^{\text {th }}$ International Conference on Road and Rail Infrastructure 17-19 May 2018, Zadar, Croatia}

TITLE

Road and Rail Infrastructure V, Proceedings of the Conference CETRA 2018

EDITED BY

Stjepan Lakušić

ISSN

$1848-9850$

ISBN

978-953-8168-25-3

DOI

10.5592/CO/CETRA.2018

PUBLISHED BY

Department of Transportation

Faculty of Civil Engineering

University of Zagreb

Kačićeva 26, 10000 Zagreb, Croatia

DESIGN, LAYOUT \& COVER PAGE

minimum d.o.o.

Marko Uremović · Matej Korlaet

PRINTED IN ZAGREB, CROATIA BY

“Tiskara Zelina”, May 2018

COPIES

500

Zagreb, May 2018.

Although all care was taken to ensure the integrity and quality of the publication and the information herein, no responsibility is assumed by the publisher, the editor and authors for any damages to property or persons as a result of operation or use of this publication or use the information's, instructions or ideas contained in the material herein.

The papers published in the Proceedings express the opinion of the authors, who also are responsible for their content. Reproduction or transmission of full papers is allowed only with written permission of the Publisher. Short parts may be reproduced only with proper quotation of the source. 
Proceedings of the

$5^{\text {th }}$ International Conference on Road and Rail Infrastructures - CETRA 2018

17-19 May 2018, Zadar, Croatia

\section{Road and Rail Infrastructure V}

\section{EDITOR}

Stjepan Lakušić

Department of Transportation

Faculty of Civil Engineering

University of Zagreb

Zagreb, Croatia 
CETRA $^{2018}$

$5^{\text {th }}$ International Conference on Road and Rail Infrastructure

17-19 May 2018, Zadar, Croatia

\section{ORGANISATION}

\section{CHAIRMEN}

Prof. Stjepan Lakušić, University of Zagreb, Faculty of Civil Engineering

Prof. emer. Željko Korlaet, University of Zagreb, Faculty of Civil Engineering

ORGANIZING COMMITTEE

Prof. Stjepan Lakušić

Prof. emer. Željko Korlaet

Prof. Vesna Dragčević

Prof. Tatjana Rukavina

Assist. Prof. Ivica Stančerić

Assist. Prof. Maja Ahac

Assist. Prof. Saša Ahac

Assist. Prof. Ivo Haladin

Assist. Prof. Josipa Domitrović

Tamara Džambas

Viktorija Grgić

Šime Bezina

Katarina Vranešić

Željko Stepan
Prof. Rudolf Eger

Prof. Kenneth Gavin

Prof. Janusz Madejski

Prof. Nencho Nenov

Prof. Andrei Petriaev

Prof. Otto Plašek

Assist. Prof. Andreas Schoebel

Prof. Adam Szeląg

Brendan Halleman

INTERNATIONAL ACADEMIC SCIENTIFIC COMMITTEE

Stjepan Lakušić, University of Zagreb, president

Borna Abramović, University of Zagreb

Maja Ahac, University of Zagreb

Saša Ahac, University of Zagreb

Darko Babić, University of Zagreb

Danijela Barić, University of Zagreb

Davor Brčić, University of Zagreb

Domagoj Damjanović, University of Zagreb

Sanja Dimter, J. J. Strossmayer University of Osijek

Aleksandra Deluka Tibljaš, University of Rijeka

Josipa Domitrović, University of Zagreb

Vesna Dragčević, University of Zagreb

Rudolf Eger, RheinMain Univ. of App. Sciences, Wiesbaden

Adelino Ferreira, University of Coimbra

Makoto Fujiu, Kanazawa University

Laszlo Gaspar, Széchenyi István University in Győr

Kenneth Gavin, Delft University of Technology

Nenad Gucunski, Rutgers University

Ivo Haladin, University of Zagreb

Staša Jovanović, University of Novi Sad

Lajos Kisgyörgy, Budapest Univ. of Tech. and Economics
Anastasia Konon, St. Petersburg State Transport Univ.

Željko Korlaet, University of Zagreb

Meho Saša Kovačević, University of Zagreb

Zoran Krakutovski, Ss. Cyril and Methodius Univ. in Skopje

Dirk Lauwers, Ghent University

Janusz Madejski, Silesian University of Technology

Goran Mladenović, University of Belgrade

Tomislav Josip Mlinarić, University of Zagreb

Nencho Nenov, University of Transport in Sofia

Mladen Nikšić, University of Zagreb

Andrei Petriaev, St. Petersburg State Transport University Otto Plašek, Brno University of Technology

Mauricio Pradena, University of Concepcion

Carmen Racanel, Tech. Univ. of Civil Eng. Bucharest

Tatjana Rukavina, University of Zagreb

Andreas Schoebel, Vienna University of Technology

Ivica Stančerić, University of Zagreb

Adam Szeląg, Warsaw University of Technology

Marjan Tušar, National Institute of Chemistry, Ljubljana

Audrius Vaitkus, Vilnius Gediminas Technical University

Andrei Zaitsev, Russian University of transport, Moscow 


\title{
AUGMENTED TRANSPORTATION: IMPLICATIONS OF AUTONOMOUS VEHICLES OUTSET IN TRAFFIC
}

\author{
Tullio Giuffrè', Sanja Šurdonja², Aleksandra Deluka-Tibljaš² \\ ${ }^{1}$ University of Enna Kore, Faculty of Engineering and Architecture, Italy \\ ${ }^{2}$ University of Rijeka, Faculty of Civil Engineering, Croatia
}

\begin{abstract}
Traffic system and its enhancement with the use of new technologies is an important element in the future development of cities. In the near future development toward traffic with autonomous vehicles is expected. Those vehicles can have a different level of autonomy but fully autonomous vehicles will result in great changes of traffic systems as well as standards for traffic infrastructure design. In this paper, a short overview of existing studies in the field of development and implementation, as well as the challenges in introducing autonomous cars, will be presented. In the paper, the results of survey named "Smart mobility survey", done in Croatia but also internationally, and the comparison of the results are presented.
\end{abstract}

Keywords: smart city, autonomous vehicles, mobility solutions

\section{Introduction}

Urban areas were always in the past changed because of development of traffic facilities and implementation of new transportation modes in the city traffic. The main change to the urban environment came with the massive use of personal cars after 2 nd world war which firstly were the development factor for the cities by enabling easier mobility but in last decades became, in many senses, the obstacle for the quality of life in urban areas.

The main negative impact that urban traffic produces today listed by [1] are noise and vibration, energy consumption, air pollution, traffic safety issues but also the loss of urban living space and visual intrusions. At the same time as solutions for resolving environmental problems in towns, European citizens emphasized: improvement of public transport, more pedestrian areas, and cycling infrastructure as well as great reduction of car traffic [2].

The concept of Smart city seems to be the solution for our cities in the future. There are several different definitions of "Smart cities" based on the various characteristics related to the adjective "Smart" and the noun "City." The Smart City commonly involves new intelligent technological tools, services, and applications integrated into platforms, providing interoperability and coordination among several sectors, which are crucial for the future life of urban communities and have impacts on the environment [3]. Therefore, "Smart cities" are an endeavor to make cities more efficient, sustainable and livable for human beings [4].

As solutions that are presently in the testing phase but regarding some sources are almost certain to be dominant on road network in next 20-30 years the autonomous vehicles (hereafter AVs) are pointed [5]. Although today the perspective of having only self-driving cars on the streets seems far away, many aspects of introducing AVs in everyday traffic are analyzed and many studies on the topic done world-wide. Introduction of self-driving erases many issues, not only connected with engineering and space planning but also with ethics, law, sociology, psychology... 
In this paper, a short overview of existing researches in the field of development and implementation as well as the challenges in introducing AVs are presented. Also, the results of survey named "Smart mobility survey" done with the aim to gather opinions on present ICT traffic services as well as on the potential introduction of autonomous vehicles in the transport system, are shown.

\section{AVs: advantages, risks, changes in road design}

There are different definitions in use for vehicles that move without driver interferation such as: automated vehicles, autonomous vehicles, self-driving vehicles and driverless vehicles. Automated vehicles are those that use on-board equipment to perform one or more driving tasks automatically. Self-driving vehicles are designed to drive autonomously, without the control of a human driver. Based on this definition "self-driving vehicles" actually, belong to the wider family of automated vehicles. Another distinction found in the literature is based on the degree to which the automated vehicle is "autonomous", relying solely on its on-board equipment to collect information, take decisions and inform tasks, or "connected", i.e. in communication with other vehicles, personal devices (e.g. smart-phones) or the surrounding traffic infrastructure to collect information and perform driving tasks [6]. However, in a literature, the term autonomous vehicles is used in relation to the highest degree of autonomy in driving. According to [7] autonomous vehicles "is designed to be capable of safely completing journeys without the need for a driver in all normally encountered traffic, road and weather conditions". In that sense, the term autonomous vehicle is used in this paper.

\subsection{Levels of automation}

The Society of Automotive Engineers (SAE International) created a six-level classification (standard J3016) of road vehicles spanning from level 0 - no automation to level 6 - full automation (Figure 1) [8].

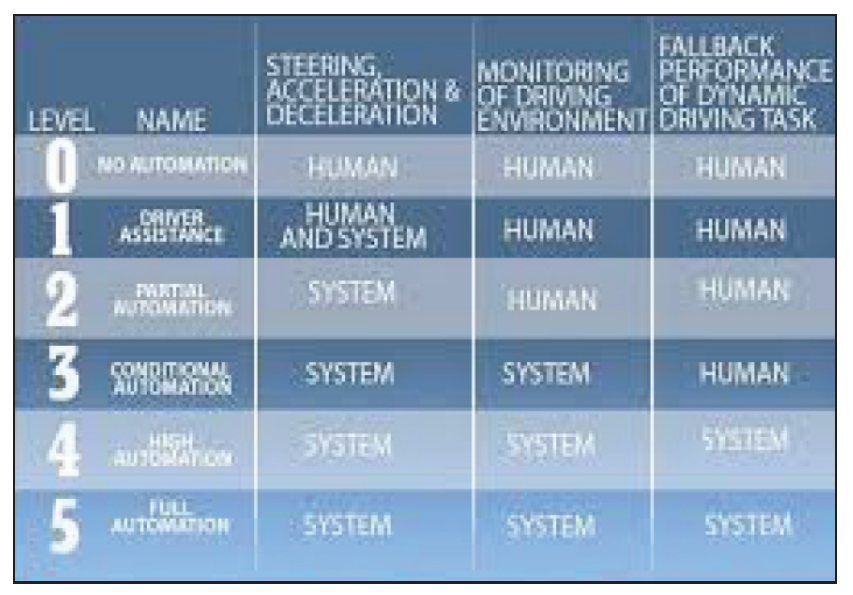

Figure 1 SAE International's Levels of Automation [8]

The European Road Transport Research Advisory Council (ERTRAC) has provided the expected date for the possible deployment of different automation systems in different SAE Levels [5]. Some of these systems are already deployed within the Level 0, Level 1 and Level 2: Lane Change Assist, Park Distance Control, Lane Departure Warning, Front Collision Warning, AntiLock System, Electronic Stability Control, Emergency Braking, Adaptive Cruise Control, Parking Assist with automated steering, Lane Keeping Assist advanced Park and Traffic Jam Assist. Level 3 systems include Traffic Jam Chauffeur and Highway Chauffeur systems which detect a slow-driving vehicle in front and then handle the vehicle both longitudinally and laterally. The possible deployment of these systems is foreseen in 2018. Highway pilot is a system 
which enables automated driving up to $130 \mathrm{~km} / \mathrm{h}$ on motorways or motorway-like roads from the entrance to exit, on all lanes, including overtaking movements. The driver must deliberately activate the system, but does not have to monitor it constantly, also vehicle-to-vehicle communication, cooperative systems, ad-hoc convoys can be created. This system is expected within level 4, in 2020-2024. Fully automated vehicle system which will be able to handle all driving without any input from the passenger/driver is expected within the Level 5 , in 2026-2030 [5]. It is evident that some levels have already been achieved and many systems are widely used in existing vehicles, although many people/drivers do not perceive it.

\subsection{Testing of AVs in the world; positive and negative impacts}

Despite the ubiquitous fear of giving up driving control, testing of AVs has already begun widely. The first testing of AVs happened during the "PROUD-Car Test 2013" event (on July 12, 2013 in Parma, Italy) when a vehicle moved autonomously and in total safety on a mixed traffic route (rural, freeway, and urban) open to public traffic, with nobody on the driver seat [9]. Today, testing of AVs in the United States is permitted by law in California, Nevada, Tennessee, Michigan and Florida. In Europe, the legal provisions allowing autonomous vehicles to participate in road traffic are introduced in Spain, Italy, Greece, Sweden, the United Kingdom and Finland [10].

The first known fatal accident involving an AVs took place in Williston, Florida on 7 May 2016 while a Tesla Model S electric car was engaged in Autopilot mode. The driver was killed in a crash with a large 18-wheel tractor-trailer. By the time of this event, the Tesla AVs (level two by SAE) overcame a total route length of 130 million miles without fatal accidents. The first known pedestrian fatality involving an AVs happened on 19 March 2018. A preliminary investigation showed that the vehicle was moving around 40 miles per hour when it struck a woman who was walking with her bicycle on the street. According to Michałowska et al. [10] these fatalities show the weaknesses of used technology, indicating that it is still the early stage of its development. Also, it shows the interdisciplinary of road safety issues, which in the combination of man-vehicle-ITS-road takes on a new dimension. According to WHO and global report on road safety 2015 [11], there are 1.25 million road traffic deaths every year, so maybe the proliferation of AVs will be the solution to the problem of road traffic accidents. Yet there are a number of positive and negative impacts of AVs according to [12]. Those are:

- safety (less crashed due to human error but more crashes due to new risk situations;

- environment (less energy use, fuel consumption, and pollution)

- mobility (less congestion, higher road capacity, more younger, elderly and disabled users, but more congestion due to increased travel demand and public transportation)

- security (less criminal and terrorist activity due to vehicle control, but more criminal and terrorist activity through hacking)

- costs (fewer crash costs, no need for professional drivers of taxis and commercial vehicles, bur higher costs due to equipment infrastructure maintenance...)

- land use (parking spaces can be located outside city centers, more green spaces but sprawled development patterns as a result of lower Value of Travel Time).

The issue with new technologies for driving experience is that they impact directly the criteria for road design. These criteria should be taken into consideration by road designers, researchers, and owners.

\section{Survey about acceptance of AVs}

Different surveys about the AVs and their impact on our future life were carried out in the world. The results of survey carried out by TNS Opinion \& Social network in the $28 \mathrm{Member}$ States of the European Union in 2014 show that $61 \%$ of respondents (69 \% in Croatia) say that 
they would feel uncomfortable travelling in an AVs and $52 \%$ (62\%) would feel uncomfortable about transporting goods in an autonomous or driverless commercial vehicle or lorry [13].

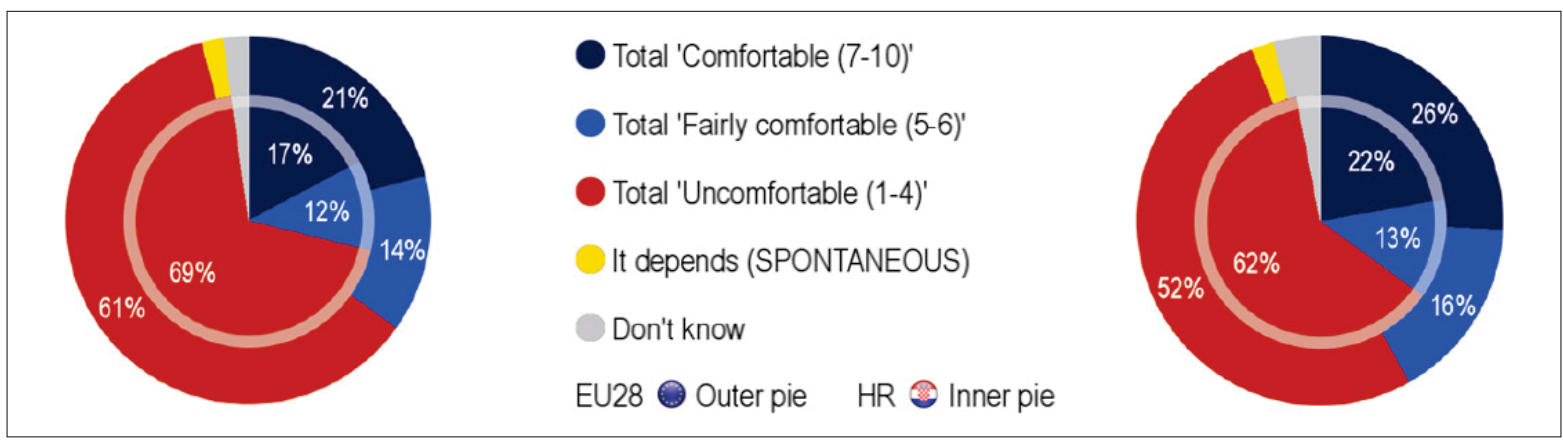

Figure 2 The acceptance of AVs; left answers to the question "Travel yourself in an autonomous car"; right answers to the question "Transport goods in autonomous cars" [13]

This and many other studies indicate a non-negligible level of reluctance. Recent studies, however $[14,15]$ display a somewhat more positive picture of the public opinion on fully automated driving. All the above indicates the need for additional mobility behaviour investigation. The transportation research group at UNIKORE during 2017 [16] designed the sample of more than 1,000 users, considering academic profiles and the field of public authorities, but also students or retired people, covering an age range between 20 and 70 years old. The geographical location of the most of sample was Italy, and $15 \%$ was from other European countries or the Middle East. This survey was a part of a project TrafficO2 - a social network for communities' urban mobility" which was funded by PON R\&C $2007-2013$.

In addition to the request for common user identification data (sex, age, marital status, city, etc.), four questions about different mobility related solutions were asked. The first question was to qualify each respondent on the availability of certain types of transport service in relation to his/her home-town. The second question was to evaluate the individual's ability to attribute "smart" to a specific service or system of transportation. The third question gathered the opinion about the impact of new technologies applied to transport systems in their daily lives. The fourth question gathered the opinion about the impact of new technologies applied to transport systems on the everyday life of their "Smart city."

Different mobility related solutions were examined in the survey: Info-mobility signage, Eticketing, Emergency services live tracking, Walking bus, Biometric scanning for check-ins, Dynamic queuing management, Dangerous goods live tracking, In-vehicle navigation tools, Bike sharing, Driverless Car, Delivery goods live-tracking, Public transport live-tracking, Vehicle Sharing, Demand Responsive Transport (Uber, Lyft, Juno, etc.), Vehicle pooling, E-parking and Telepass/E-pass.

The same survey was done in Croatia, in January 2018, with the sample of 185 users, mostly young people (20-30 years), and mostly among students and people working in educational institutions. The results of Croatian survey showed a good familiarity (more than $50 \%$ of the sample have used it) with in-vehicle navigation services, infomobility signage, demand responsive transport (DRT) and delivery goods tracking, while the results of UNIKORE survey showed a good familiarity with e-ticketing and in-vehicle navigation services. Only a few have experienced innovations such as driverless cars (AVs), dynamic queuing management or emergency vehicle live tracking (Figure 3).

In Croatian survey, in-vehicle navigation tools, public transportation live tracking and delivery goods live tracking stand out as the "smartest" mobility related solutions because at the moment they are most used and recognized (as shown in Figure 3). In UNIKORE survey as the "smartest" mobility related solutions stand out E-ticketing and public transportation live tracking (Figure 4). AVs is also more recognized as "smart" mobility related solution comparing to Croatian survey. 


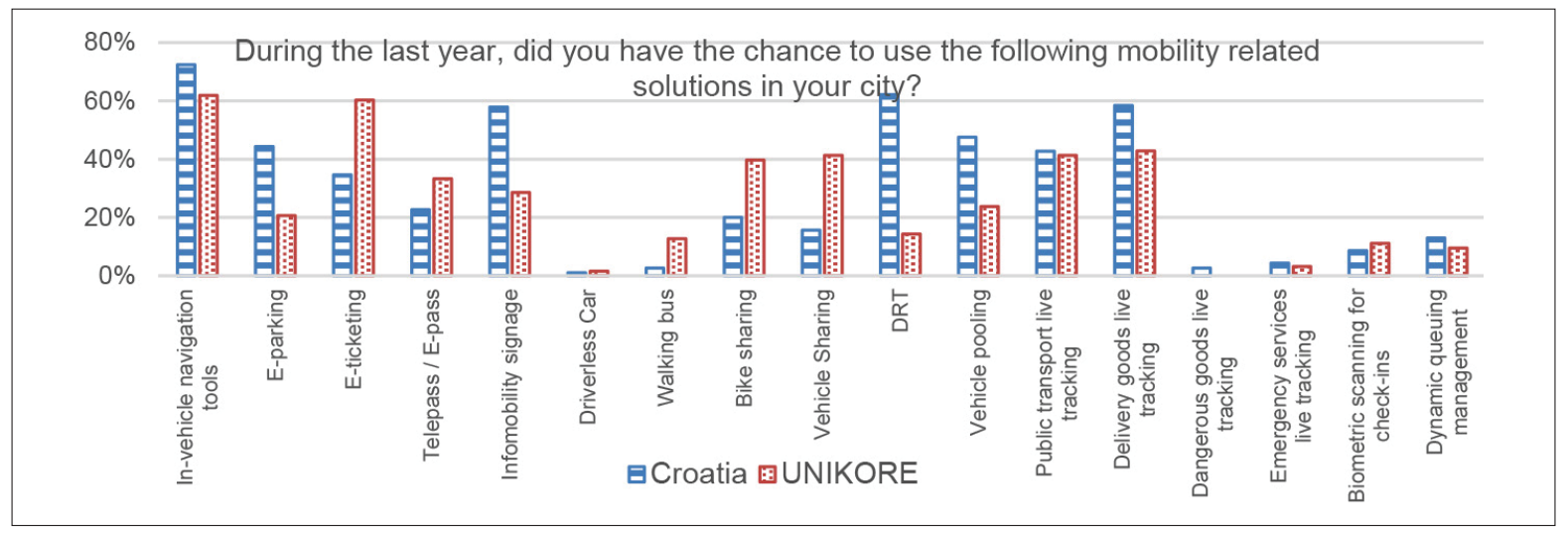

Figure 3 The familiarity of different mobility related solutions

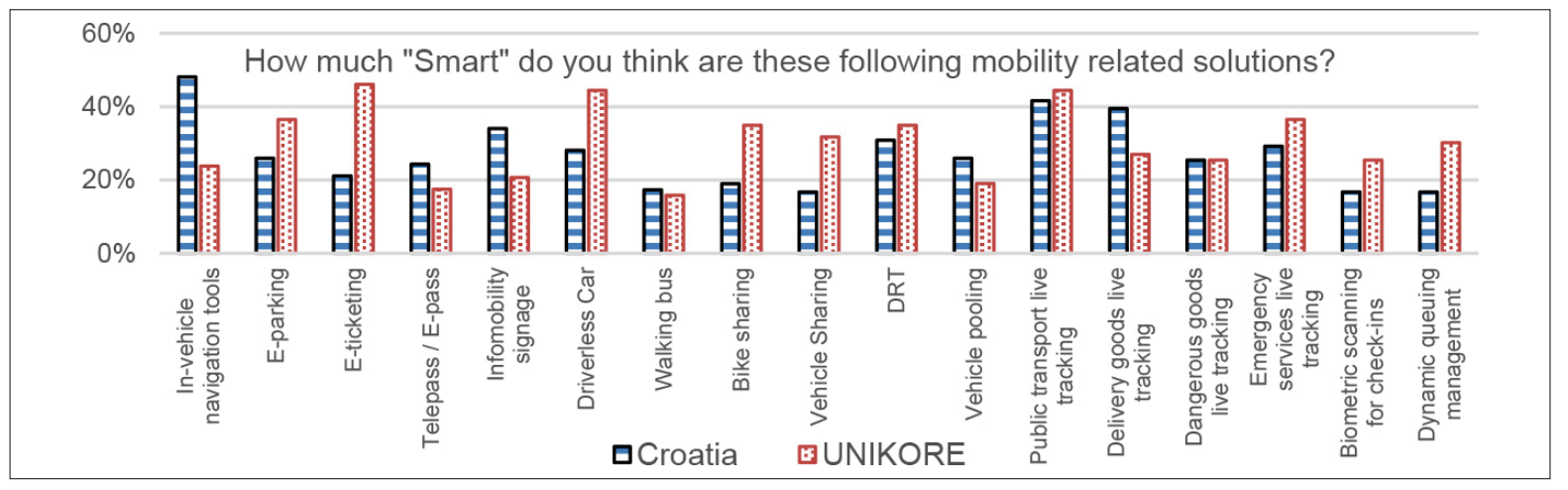

Figure 4 The opinion about different mobility related solutions

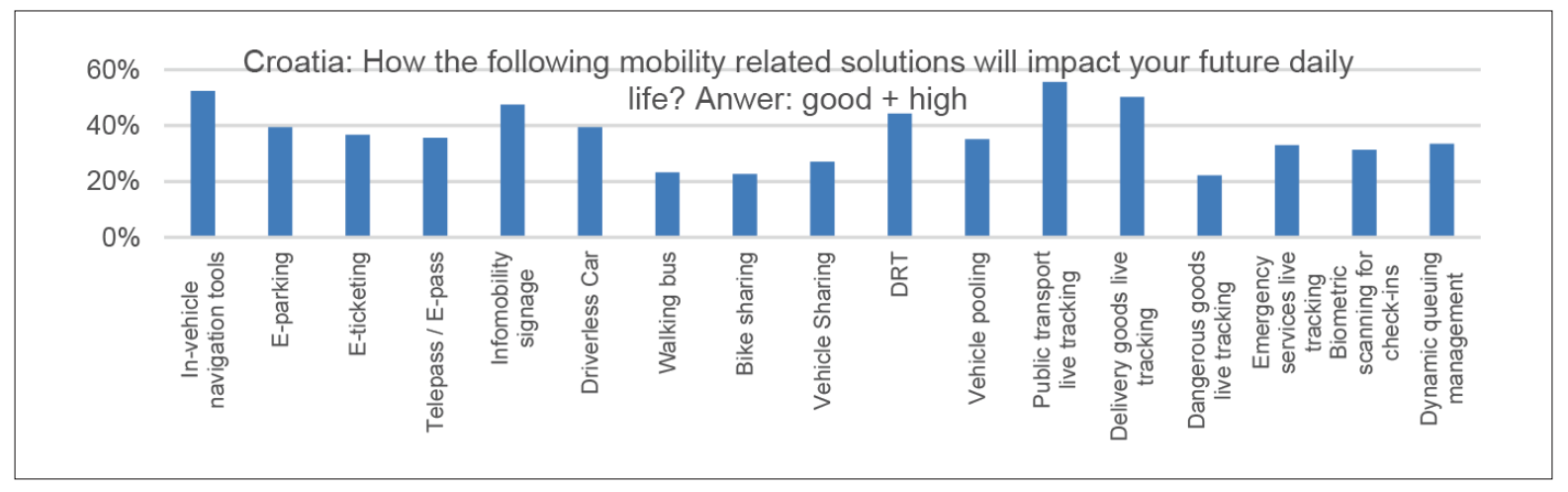

Figure 5 The impact of different mobility solutions on future daily life - Croatia

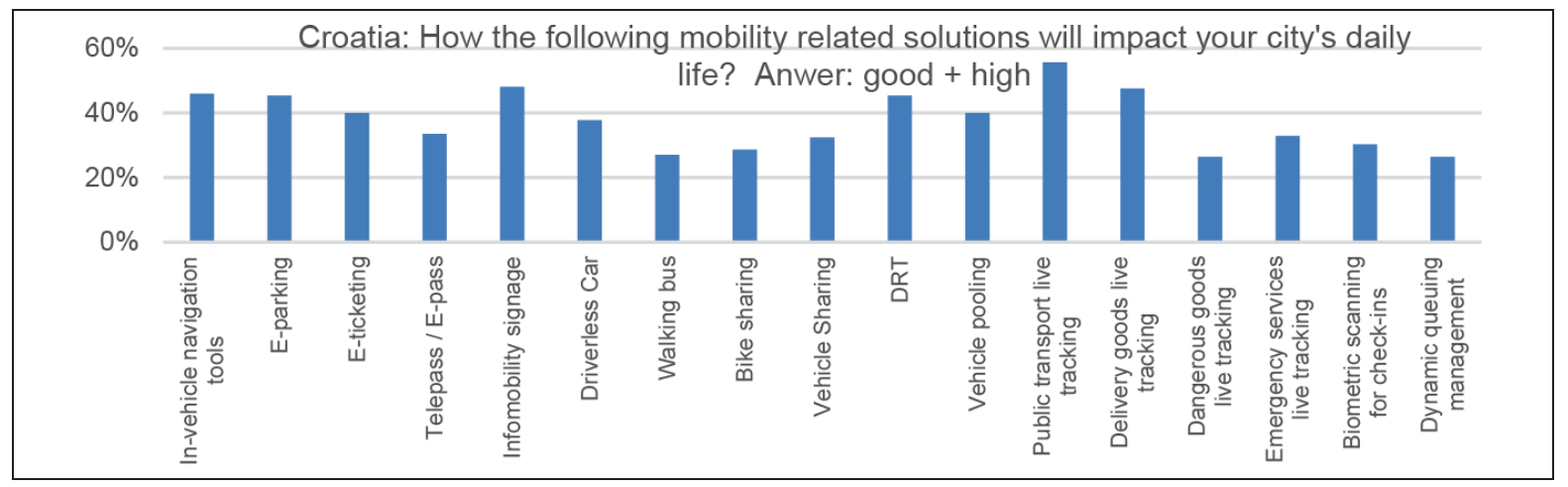

Figure 6 The impact of different mobility solutions on city`s daily life - Croatia 
As shown in Figure 5 and 6, in Croatia people expect that in-vehicle navigation tools, infomobility signage, DRT (demand responsive transport), public transportation live tracking and delivery goods live tracking will have the biggest impact (answers: good+high) on their future daily life and city's daily life. All of the above is already used in everyday life (Figure 3) and is recognized as a "smart" mobility related solution (Figure 4). However, besides the above mentioned, the use of AVs is also highlighted, more than $35 \%$ of the sample expects to use AVs in everyday life in the future. The expected impact of AVs is different according to Croatia and UNIKORE survey if analyzing family status (Figure 7). The greatest impact on future daily life is expected by singles in Italy and by families in Croatia. Among those who answered that AVs will have a good or high impact on their future daily life are mostly people 20-40 years old, as expected.

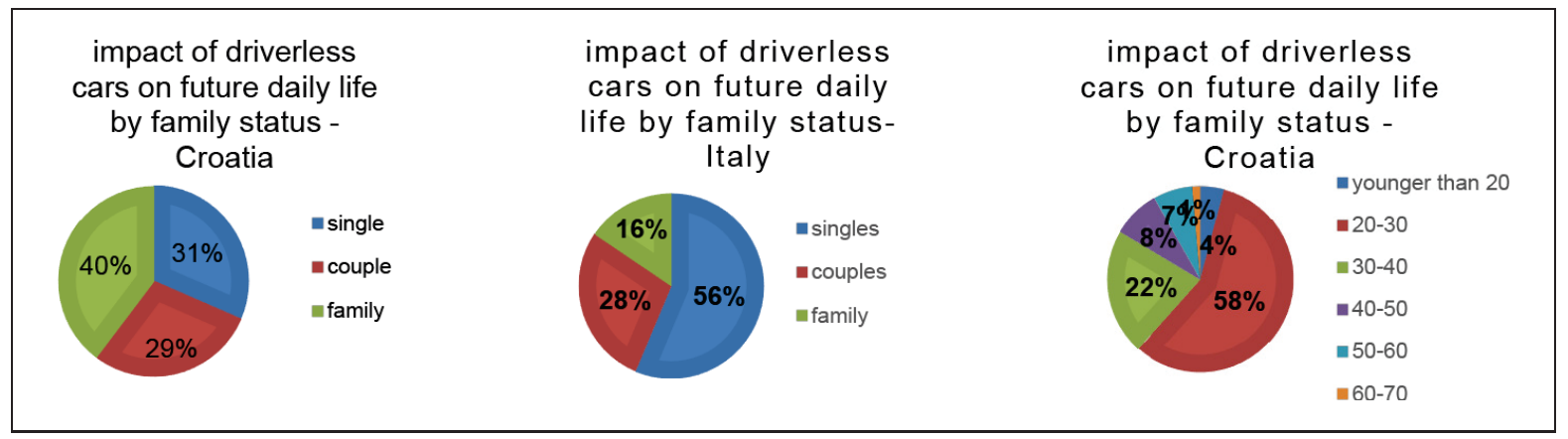

Figure 7 Impact of AVs on future daily life.

\section{Conclusions}

Traffic systems in the cities rely today a lot on used IT solutions and it can be expected that the same trend will continue in the future. The major change in traffic systems will happen with the implementation of AVs. The surveys done in different EU countries show that mostly younger citizens (20-40 years) are open to the possible use of AVs but at the same time many of them have the ubiquitous fear of giving up driving control. Considering the above, it can be concluded that the introduction of the positive and negative aspects of different mobility solutions is necessary so that each of these solutions become a reality in future everyday life. As for the traffic and civil engineers in the next years, it will be important to test implication of $\mathrm{AVs}$ in road design and traffic management in order to prevent possible problems, especially regarding traffic safety.

\section{References}

[1] European Commission. (2004). Reclaiming city streets for people: Chaos or quality of life? Luxembourg: Office for Official Publications of the European Communities

[2] EC (1999), What Do Europeans Think about the Environment? Culture and Audiovisual Media, Brussels.

[3] Perboli, G., De Marco, A., Perfetti, F., Marone, M.A.: New Taxonomy of Smart City Projects. In Proceedings of 17th Meeting of the EURO Working Group on Transportation, July 2014, Sevilla, Spain

[4] Sujata, J., Saksham, S., Tanvi, G., Shreya, D.: Developing Smart Cities: An Integrated Framework. Proceedings of 6th International Conference on Advances on Computing \& Communications, September 2016, Cochin, India.

[5] Automated Driving Roadmap, European Road Transport Research Advisory Council, ERTRAC Task Force ‘Connectivity and Automated Driving', Version 5.0 (2015) 
[6] EP: Research for TRAN Committee - Self-piloted cars: The future of road transport? Study, DirectorateGeneral for Internal Policies Policy Department B: Structural and Cohesion Policies, European Parliament, Committee on Transport and Tourism, Brussels (2016)

[7] DfT. The Pathway to Driverless Cars: Summary report and action plan. Department for Transport. 2015

[8] SAE International - On-Road Automated Vehicle Standards Committee, Taxonomy and Definitions for Terms Related to On-Road Motor Vehicle Automated Driving Systems, Information Report, January 2014

[9] PROUD-Car Test 2013 http://vislab.it/proud-en. accessed on 23 Mar 2018

[10] Michałowska, M., Ogłoziński, M.: Autonomous Vehicles and Road Safety. In: Mikulski J. (eds) Smart Solutions in Today's Transport. TST 2017. Communications in Computer and Information Science, vol 715. Springer, Cham WHO global report on road safety 2015

[11] World Health Organization. Global status report on road safety 2015. Geneva, Switzerland: WHO, 2015

[12] Alonso Raposo, M., Ciuffo, B., Makridis, M., Thiel, C.: The r-evolution of driving: from Connected Vehicles to Coordinated Automated Road Transport (C-ART), Part I: Framework for a safe \& efficient Coordinated Automated Road Transport (C-ART) system, EUR 28575 EN, doi:10.2760/225671.

[13] EUROBAROMETER 82.4, accessed on 23 Mar 2018, http://ec.europa.eu/commfrontoffice/ publicopinion/archives/ebs/ebs_427_fact_hr_en.pdf

[14] Kyriakidis, M., Happee, R., de Winter, J.C.F.: 'Public opinion on automated driving: Results of an international questionnaire among 5000 respondents', Transportation Research F, 32, pp. 127-140, 2015.

[15] Payre, W., Cestac, J., Delhomme, P.: 'Intention to use a fully automated car: Attitudes and a priori acceptability', Transportation Research F, 27, pp. 252-263, 2014.

[16] Giuefre, T., Di Dio, S.: "Smart transportation as a driver of transition: big data management, behavioral change and the shift to automated vehicles. in Smart Cities: Technologies, Challenges and Future Prospects, Edition Novapublishers, NY (USA), 2017 